\title{
Congenital mitral regurgitation due to 'posterior reinsertion' of chordae tendineae
}

\author{
G. Bevilacqua \\ From the Institute of Pathological Anatomy and Histology, Medical School, University of Pisa, Pisa, Italy
}

A rare type of congenital mitral regurgitation is presented for the first time as an isolated cardiac anomaly. The malformation consists of a particular arrangement of the chordae tendineae of the posterior leaflet: the chordae, leaving the free margin or the undersurface, insert into the latter once again. $A$ definition of the anomaly and a classification of all the chordal anomalies found in congenital mitral regurgitation are proposed. The clinical picture is briefly reported.

Congenital mitral regurgitation is the consequence of anomalies involving, individually or collectively, the different components of the mitral valve, i.e. the ostium, the leaflets, the chordae tendineae, and the papillary muscles. Dilatation of the valve ring is generally secondary to enlargement of the left ventricle, the left atrium, or both, due to congenital anomalies causing increased pressures in the left cardiac chambers (Carney et al., 1962; Keith, 1962; Flege, Vlad, and Ehrenhaft, 1967; Easthope et al., 1969). The leaflets may be absent (Kjellberg et al., 1959; Malers et al., 1960), hypoplastic (Carney et al., 1962; Flege et al., 1967; Titus, 1969), or redundant (Raghib et al., 1965; Titus, 1969). A cleft of varying depth (Schraft and Lisa, 1950; Campbell and Missen, 1957; Wakai and Edwards, 1958; Edwards and Burchell, 1958; Creech, Ledbetter, and Reemtsma, 1962; Hudson, 1965; Flege et al., 1967; Titus, 1969; Messmer, Hallman, and Cooley, 1970) or several fenestrations (Keith, 1962; Flege et al., 1967) may be present. The valve may also show accessory leaflets (Carney et al., 1962) or subdivision into smaller cusps (Hudson, 1965). Titus (1969) refers to the absence of commissural leaflet tissue, and Barillon, Grosgogeat, and Lenègre (1962) describe the fusion of the cusps at the commissures. Duplication of the mitral orifice has been reported several times (Schraft and Lisa, 1950; Prior, 1953; Edwards and Burchell, 1958; Wakai and Edwards, 1958; Keith, 1962; Rosenberg and Roberts, 1968).

A local absence of chordae is described by Flege et al. (1967); an unspecified 'absence' is reported by Easthope et al. (1969). Short chordae are described by Edwards and Burchell (1958), Flege et al.
(1967), and Easthope et al. (1969), while Carney et al. (1962) mention a shortening of the chordae so extreme that the anterior leaflet inserted directly into the papillary muscles. Chordae of abnormal length are described by Raghib et al. (I965), Flege et al. (1967), and Davachi, Moller, and Edwards (1971). Chordae may insert anomalously into the ventricular wall (Malers et al., 1960; Keith, 1962; Davachi et al., 197I) or into the opposite leaflet (Edwards and Burchell, 1958).

The presence of a single papillary muscle (Shone et al., 1963; Terzaki et al., 1968; Glancy et al., I97I) or two papillary muscles very close together (Davachi et al., 197I), into which the chordae tendineae from both mitral leaflets insert are described as 'parachute mitral valve'. Generally this anomaly causes a stenosis, but it is sometimes the cause of regurgitation (Glancy et al., 1971). Another peculiar malformation consists of an arcade formed by the papillary muscles and the anterior leaflet, named by Layman and Edwards (I967) 'anomalous mitral arcade'. Hypoplasia and abnormal position of papillary muscles have also been mentioned (Moller et al., 1964; Al Omeri et al., 1965; Davachi et al., 1971).

Congenital mitral regurgitation is often associated with other cardiac lesions. Some instances form an integral part of more complex malformations, such as a cleft in the anterior leaflet, anomalous insertion of the chordae or a duplication of the valve orifice in the different grades of endocardial cushion defect (Campbell and Missen, 1957; Edwards and Burchell, 1958; Wakai and Edwards, 1958; Al Omeri et al., 1965; Rosenberg and Roberts, 1968). Others are a consequence of cardiac 
malformations, such as scarring of papillary muscles, thickening and shortness of the chordae, abnormal position of the papillary muscles, and dilatation of the valve ring due to anomalous origin of the left coronary artery from the pulmonary trunk (Noren et al., 1964; Messmer et al., 1970; Davachi et al., 1971). Others yet are due to primary endocardial fibroelastosis (Edwards and Burchell, 1958; Moller et al., 1964; Messmer et al., 1970), to endocardial fibroelastosis secondary to aortic stenosis, coarctation of the aorta (Moller et al., 1964; Easthope et al., 1969; Messmer et al., 1970), and persistent ductus arteriosus (Linde and Adams, 1959). In Marfan's syndrome direct involvement of the mitral valve may give rise to a lengthening of the chordae or a redundancy of the leaflets with consequent regurgitation (Raghib et al., 1965).

The isolated form remains a very rare lesion, though reports are becoming more frequent. In the present study a most unusual type of isolated malformation of the chordae tendineae is described.

\section{Case report}

The patient, a 58-year-old man, had served in the Navy for 36 years. In 1966, at the age of 53, he began to develop leg oedema, moderate dyspnoea, a postprandial feeling of epigastric oppression, and a bitter taste in the mouth. His family doctor diagnosed mitral insufficiency and prescribed treatment with digitalis and diuretics. In 1969 the patient was admitted to a medical department of Pisa University on account of worsening dyspnoea and the appearance of anasarca. The diagnosis was mitral and tricuspid regurgitation with congestive heart failure, for which digitalis and diuretics were given. There was no history of rheumatic fever. A valve replacement was recommended, but was not carried out because of increasing renal and hepatic insufficiency. In 1971 the patient was again admitted to hospital on account of worsening of his symptoms, where, after several episodes of ventricular fibrillation, he died.

\section{Physical findings}

The examination of the thorax revealed an enlarged area of cardiac dullness with an apical pansystolic murmur, a third sound, a low sternal pansystolic murmur (intensified during inspiration), an ejection murmur in the aortic area, and a splitting of the second sound. Examination of the abdomen showed enlargement and tenderness of the liver, whose lower border was $4 \mathrm{~cm}$ below the right costal margin in the midclavicular line, and enlargement of the spleen, with the upper limit at the eighth intercostal space and the lower pole $4 \mathrm{~cm}$ below the left costal margin during deep inspiration.

\section{Laboratory findings}

The electrocardiogram showed biventricular hypertrophy and left atrial enlargement. Cardiac catheterization showed severe (grade 3/4) mitral and tricuspid insufficiency, with pronounced pulmonary hypertension (Table I). The bromsulphalein excretion was I2 per cent at 30 minutes. The blood urea increased to $165 \mathrm{mg}$ ! $100 \mathrm{ml}$. The plasma creatinine was $\mathrm{I} \cdot 95 \mathrm{mg} / 100 \mathrm{ml}$, the creatinine $50 \mathrm{mg} / 100 \mathrm{ml}$, and the creatinine clearance $4 \mathrm{I} \mathrm{ml} / \mathrm{min}$.

TABLE I Haemodynamic values $(\mathrm{mmHg})$

\begin{tabular}{|c|c|c|c|}
\hline & Systolic & Mean & Diastolic \\
\hline Right atrium & V 21 & 13 & - \\
\hline Right ventricle & 87 & - & 15 \\
\hline Pulmonary artery & 88 & 57 & 40 \\
\hline PA wedge & v 28 & 22 & - \\
\hline Left ventricle & 76 & - & 8 \\
\hline Aorta & 75 & - & 46 \\
\hline
\end{tabular}

\section{Pathological findings}

Necropsy revealed general cardiac enlargement with a weight of $800 \mathrm{~g}$. The orifices of the atrioventricular, aortic, and pulmonary valves were all dilated, and the coronary sinus enlarged. The myocardium was hypertrophied, particularly in the right ventricle, in consequence of long-standing pulmonary hypertension (Table 2). The left atrial endocardium was strikingly thickened and showed some evident 'jet lesions' (Fig. I, 2). The endocardium of the right atrium and ventricle and the leaflets of the tricuspid valve were also thickened to a lesser degree. The most interesting changes involved the posterior leaflet of the mitral valve: it was c. $55 \mathrm{~mm}$ wide, c. $20 \mathrm{~mm}$ long, and c. $2 \mathrm{~mm}$ thick and protruded into the atrium in the form of a flattened hood (Fig. I, 2). While a few abnormally thick chordae

TABLE 2 Heart measurements $(\mathrm{cm})$

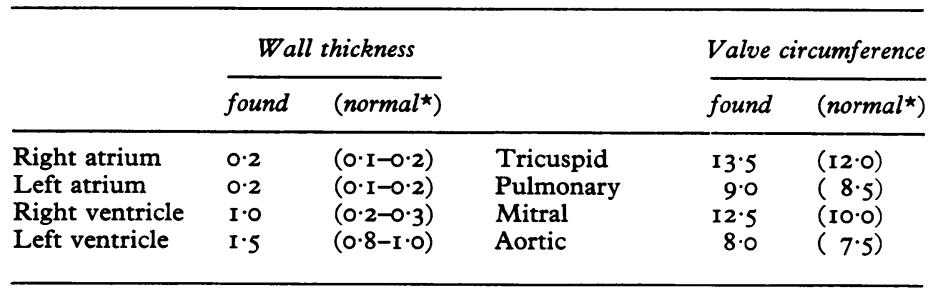

* Saphir (1958). 


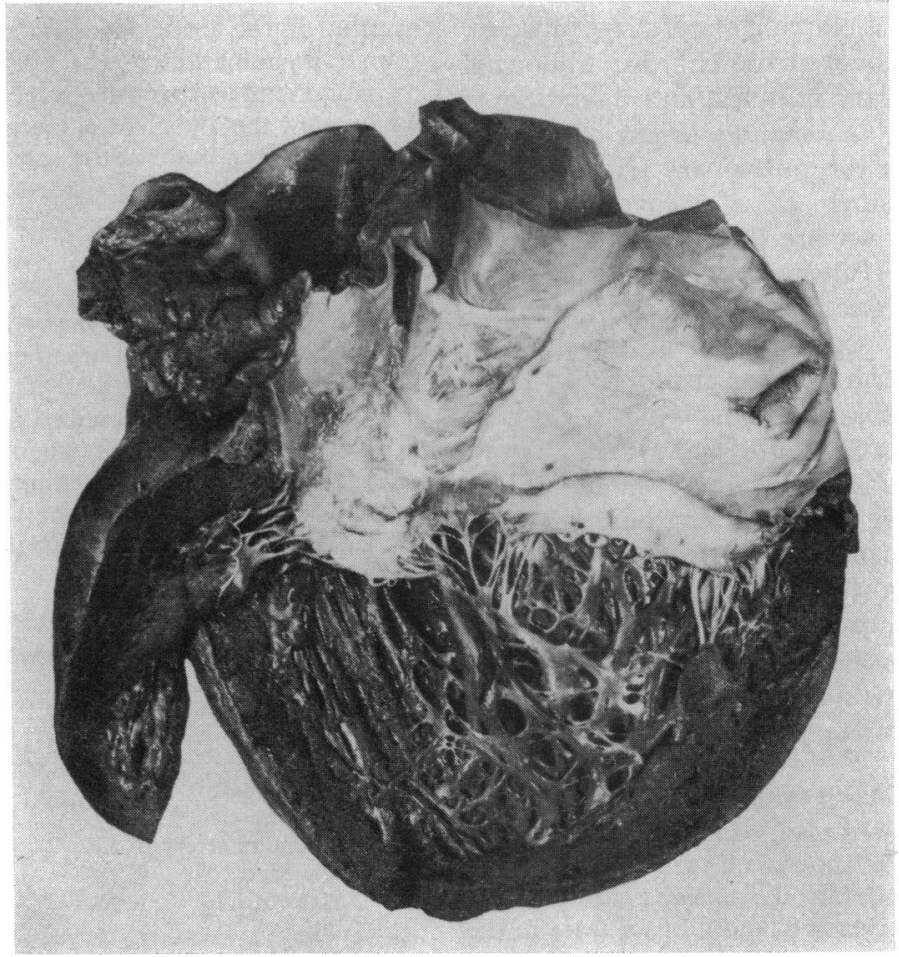

FIG. I General view of the opened left heart.

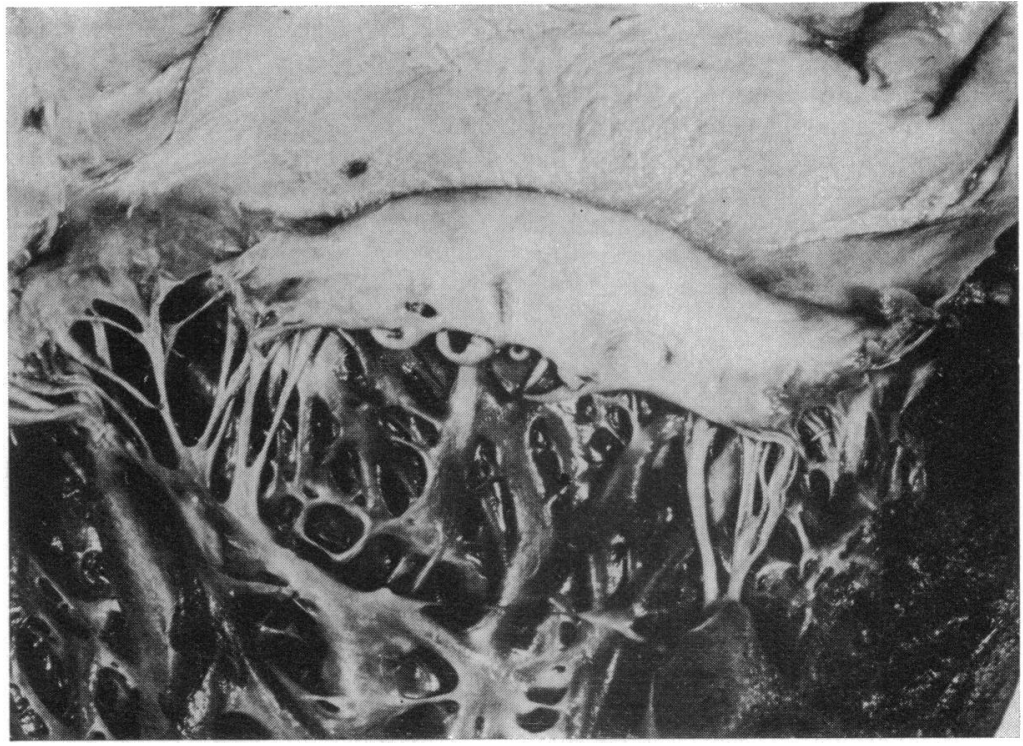

FIG. 2 Atrial surface of the posterior leaflet of the mitral valve. Note that its only complete chordae are thickened and are inserted into either end of it, while in its central part only a few thickened chordae are visible arising at or near its free edge and then bending upwards and backwards. The fenestration near the free edge is an artefact. The endocardium of the left atrial wall is thickened and rugose. 


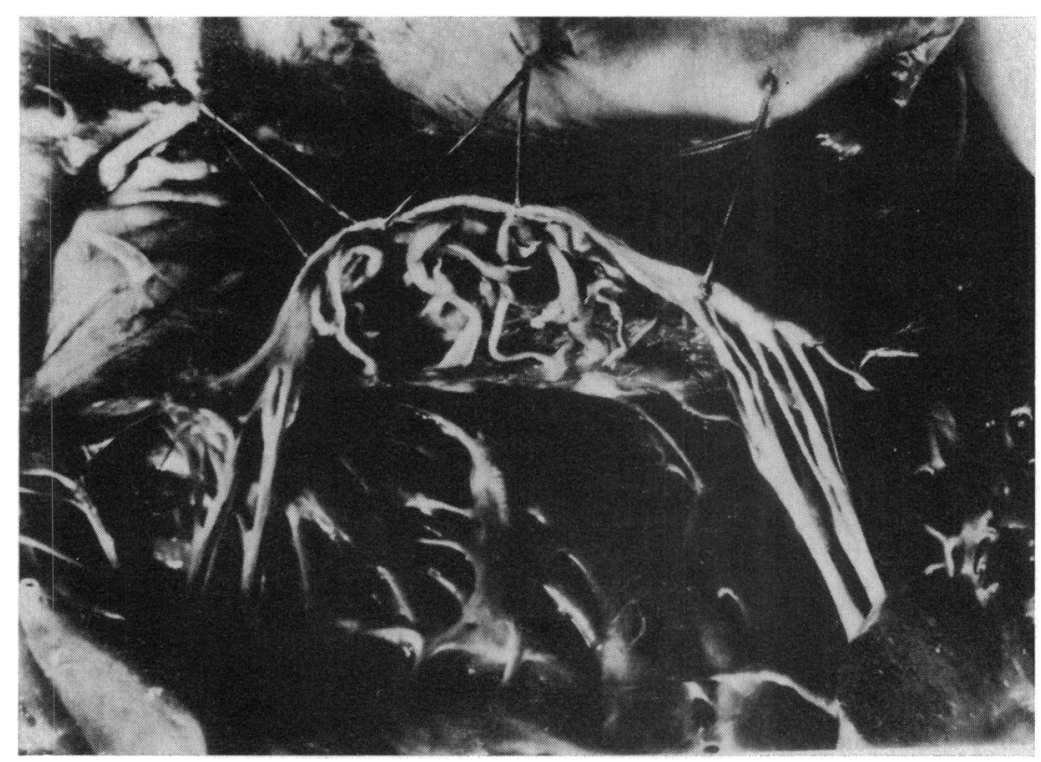

FIG. 3 Ventricular surface of the posterior leaflet of the mitral valve: note the 'reinsertion' of the chordae tendineae.

ran from the papillary muscles (normal in number and situation) to either end of this leaflet, to insert into the free margin or into the distal ventricular surface, the middle three-fifths of the free margin appeared - from the atrial aspect - devoid of chordae (Fig. I, 2). Examination of the ventricular surface of the leaflet, however, revealed numerous chordal structures so disposed that, arising from the free margin or the undersurface, they extended in a basal direction to insert into the clear zone or into the basal zone of the ventricular surface (Fig. 3). A few inserted into a slight linear thickening of the endocardium of the posterior wall of the left ventricle, just below the base of the leaflet. Except at their ends, these anomalous chordae were free. There was no macroscopical evidence of an inflammatory process (Fig. 3). As a res'ult of this chordal anomaly the valve was regurgitant. Microscopical examination showed the abnormal chordae tendineae to be composed of bundles of avascular collagenous connective tissue; neither the chordae nor the leaflet showed evidence of inflammation.

The anterior leaflet of the mitral valve showed thickening only. No further abnormality was found in the heart.

The lungs, liver, and spleen showed characteristic changes of chronic passive congestion, while the other organs were normal.

\section{Discussion}

From the gross and microscopical findings described, it is concluded that the lesion represents a congenital anomaly of the mitral valve, i.e. a particular form of the 'anomalous chordae tendineze' type. There is only one similar case described
(Prior, 1953), in which, however, the chordae were for the most part fused in an irregular mass and 'an interauricular septal defect was present at the anterior margin of the fossa ovalis (ostium secundum). The defect measured $1.5 \mathrm{~cm}$ in diameter and although it communicated with the left auricle, it tended to be partially covered by a valve-like structure on the left side.' Though in this case the original description may suggest the possibility that the atrial septal communication was simply a dilatation of the fossa ovalis, originally the site of a valvular patency, due to the enlargement of the left atrium from chronic mitral regurgitation, nevertheless the mitral abnormality was not isolated. Both patients survived into adult life - to 26 years in Prior's case and to 58 years in the present one. The pathogenesis of the lesion probably lies in an error in the formation of the myocardial diverticula

TABLE 3 Chordal anomalies in congenital mitral regurgitation
I) Absence
2) Abnormal length
3) Abnormal shortness
4) Anomalous insertion:
a) into the ventricular wall
b) into the other leaflet
c) posterior reinsertion 
during the early stages of development of the atrioventricular valves (Odgers, 1939). In view of the peculiar way in which the chordae, after leaving the leaflet, insert into it again, this rare anomaly may properly be called 'posterior reinsertion of the chordae tendineae'. It has been so identified in Table 3, which attempts to classify the various anomalies of the chordae tendineae encountered in congenital mitral insufficiency.

\section{References}

Al Omeri, M., Bishop, M., Oakley, C., Bentall, H. H., and Cleland, W. P. (1965). The mitral valve in endocardial cushion defects. British Heart fournal, 27, I6I.

Barillon, A., Grosgogeat, Y., and Lenègre, J. (1962). L'insuffisance mitrale congénitale pure. Archives des Maladies $d u$ Coeur et des Vaisseaux, 55, 1338.

Campbell, M., and Missen, G. A. K. (1957). Endocardial cushion defects. Common atrio-ventricular canal and ostium primum. British Heart fournal, 19, 403.

Carney, E. K., Braunwald, E., Roberts, W. C., Aygen, M., and Morrow, A. G. (1962). Congenital mitral regurgitation. Clinical, hemodynamic and angiocardiographic findings in nine patients. American fournal of Medicine, 33, 223.

Creech, O. J., Ledbetter, M. K., and Reemtsma, K. (I962). Congenital mitral insufficiency with cleft posterior leaflet. Circulation, 25, 390.

Davachi, F., Moller, J. H., and Edwards, J. E. (197I). Diseases of the mitral valve in infancy. An anatomic analysis of 55 cases. Circulation, 43, 565.

Easthope, R. N., Tawes, R. L., Bonham-Carter, R. E., Aberdeen, E., and Waterston, D. J. (1969). Congenital mitral valve disease associated with coarctation of the aorta. A report of 39 cases. American Heart fournal, 77, 743.

Edwards, J. E., and Burchell, H. B. (1958). Pathologic anatomy of mitral insufficiency. Proceedings of the Staff Meetings of the Mayo Clinic, 33, 498.

Flege, J. B., Jr., Vlad, P., and Ehrenhaft, J. L. (1967). Congenital mitral incompetence. Fournal of Thoracic and Cardiovascular Surgery, 53, 138.

Glancy, D. L., Chang, M. Y., Dorney, E. R., and Roberts, W. C. (1971). Parachute mitral valve. Further observations and associated lesions. American fournal of Cardio$\log y, 27,309$.

Hudson, R. E. B. (1965). Cardiovascular Pathology. Edward Arnold, London.

Keith, J. D. (1962). Congenital mitral insufficiency. Progress in Cardiovascular Diseases, 5, 264.

Kjellberg, S. R., Mannheimer, E., Rudhe, U., and Jonsson, B. (1959). Diagnosis of Congenital Heart Disease, 2nd ed. Year Book Publishers, Chicago.

Layman, T. E., and Edwards, J. E. (1967). Anomalous mitral arcade. A type of congenital mitral insufficiency. Circulation, 35, 389 .
Linde, L. M., and Adams, F. H. (1959). Mitral insufficiency and pulmonary hypertension accompanying patent ductus arteriosus. Report of three cases. American fournal of Cardiology, 3, 740.

Malers, E., Björk, V. O., Cullhed, I., and Lodin, H. (1960). Transposition functionally totally corrected, associated with 'mitral' insufficiency. American Heart fournal, 59, $8 \mathrm{r} 6$.

Messmer, B. J., Hallman, G. L., and Cooley, D. A. (1970). Congenital mitral insufficiency. Results in unusual lesions. Annals of Thoracic Surgery, 10, 450.

Moller, J. H., Lucas, R. V., Adams, P., Jr., Anderson, R. C., Jorgens, J., and Edwards, J. E. (I964). Endocardial fibroelastosis. A clinical and anatomic study of 47 patients with emphasis on its relationship to mitral insufficiency. Circulation, 30, 759.

Noren, G. R., Raghib, G., Moller, J. H., Amplatz, K., Adams, P., Jr., and Edwards, J. E. (1964). Anomalous origin of the left coronary artery from the pulmonary trunk with special reference to the occurrence of mitral insufficiency. Circulation, 30, 171.

Odgers, P. N. B. (1939). The development of the atrioventricular valves in man. fournal of Anatomy, 73, 643.

Prior, J. T. (1953). Congenital anomalies of the mitral valve: two cases associated with long survival. American Heart Fournal, 46, 649.

Raghib, G., Jue, K. L., Anderson, R. C., and Edwards, J. E. (1965). Marfan's syndrome with mitral insufficiency. American fournal of Cardiology, 16, 127.

Rosenberg, J., and Roberts, W. C. (1968). Double orifice mitral valve. Study of the anomaly in two calves and a summary of the literature in humans. Archives of Pathology, 86, 77.

Saphir, O. (1958). Autopsy Diagnosis and Technic. HoeberHarper, New York.

Schraft, W. C., and Lisa, J. R. (1950). Duplication of the mitral valve. American Heart fournal, 39, 136.

Shone, J. D., Sellers, R. D., Anderson, R. C., Adams, P., Lillehei, C. W., and Edwards, J. E. (1963). The developmental complex of parachute mitral valve, supravalvular ring of left atrium, subaortic stenosis, and coarctation of aorta. American fournal of Cardiology, 11, 714.

Terzaki, A. K., Leachman, R. D., Ali, M. K., Hallman, G. L., and Cooley, D. A. (1968). Successful surgical treatment for 'parachute mitral valve' complex. Report of two cases. fournal of Thoracic and Cardiovascular Surgery, 56, I.

Titus, J. L. (1969). Congenital malformations of the mitral and aortic valves and related structures. Diseases of the Chest, 55, 358.

Wakai, C. S., and Edwards, J. E. (1958). Pathologic study of persistent common atrioventricular canal. American Heart fournal, 56, 779.

Requests for reprints to Dr. G. Bevilacqua, Institute of Pathological Anatomy and Histology, Medical School, University of Pisa, Via Roma 57, 56100 Pisa, Italy. 